\title{
Combination of Organocatalytic Oxidation of Alcohols and Organolithium Chemistry (RLi) in Aqueous Media, at Room Temperature and Under Aerobic Conditions
}

.Received 00th January 20xx, Accepted 00th January 20xx

DOI: $10.1039 / x 0 x x 00000 x$

\author{
David Elorriaga, ${ }^{\mathrm{a}, \uparrow}$ María Jesús Rodríguez-Álvarez, ${ }^{\mathrm{a}, \uparrow}$ Nicolás Ríos-Lombardía, ${ }^{\mathrm{b}}$ Francisco Morís, ${ }^{\mathrm{b}}$ \\ Alejandro Presa Soto, ${ }^{c}$ Javier González-Sabín, ${ }^{*, b}$ Eva Hevia, ${ }^{*, d}$ and Joaquín García-Álvarez. ${ }^{*, a}$
}

\begin{abstract}
A tandem protocol to access tertiary alcohols has been developed which combines the organocatalytic oxidation of secondary alcohols to ketones followed by their chemoselective addition by several RLi reagents. Reactions take place at room temperature, under air and in aqueous solutions, a trio of conditions that are typically forbidden in polar organometallic chemistry.
\end{abstract}

As Nature's solvent in biological processes, the use of water as a medium in organic synthesis ${ }^{1}$ is widely recognized as an important strategy towards developing sustainable chemical processes that implement some of the most significant Principles of Green Chemistry $^{2}$. Water is abundant, non-toxic, cost-effective, nonflammable, renewable, and non-volatile ${ }^{3}$ and it has already shown an enormous potential as a versatile reaction medium in many cornerstone organic transformations such as oxidations, reductions, reductive aminations, pericyclic reactions to name just a few, ${ }^{1}$ as well as in a myriad of transition-metal-catalyzed reactions. ${ }^{4}$ Furthermore, in many cases water is not only a greener alternative to toxic organic solvents but can also be a superior medium, improving reactivities and selectivities, simplifying work up procedures and facilitating catalyst recycling. ${ }^{5}$ Nevertheless, despite these key advantages, until recently, water has shown very little promise as a solvent to carry out organolithium chemistry with only a few examples in the literature. ${ }^{6}$ This is probably as a consequence of the common assumption that these polar reagents rapidly decompose in contact with this solvent. In fact, the use of protective inert atmosphere conditions and stringently dry organic solvent along with strict control of the

\footnotetext{
a. Laboratorio de Compuestos Organometálicos y Catálisis (Unidad Asociada al CSIC). Departamento de Química Orgánica e Inorgánica, (IUQOEM), Centro de Innovación en Química Avanzada (ORFEO-CINQA), Facultad de Química, Universidad de Oviedo, E-33071, Oviedo, Spain.

b. EntreChem SL, Vivero Ciencias de la Salud. Santo Domingo de Guzmán, 33011 , Oviedo, Spain.

Departamento de Química Orgánica e Inorgánica, (IUQOEM) Facultad de Química, Universidad de Oviedo, E-33071, Oviedo, Spain.

d. Department für Chemie und Biochemie, Universität Bern, CH3012, Bern, Switzerland

† These authors contributed equally to the work.

Electronic Supplementary Information (ESI) available: [details of any supplementary information available should be included here]. See DOI: 10.1039/x0xx00000x
}

reaction temperatures (usually of the order of $-78^{\circ} \mathrm{C}$ ) are usually mandatory to avoid fast degradation and control the exceptionally high reactivity of organolithium reagents. ${ }^{7}$ However, what was thought impossible just a few years ago, an aerobic sustainable polar organometallic chemistry, is now starting to look distinctly possible. ${ }^{6,8}$ Thus, Capriati has reported the chemoselective addition of organolithiums to carbonyl compounds ${ }^{8 d}$ and to nitriles and imines $^{8 \mathrm{~h}}$ under on water conditions as well as palladium catalyzed direct cross-couplings of RLi and hetero(aryl) halides. ${ }^{8 i}$ Furthermore bioinspired Deep Eutectic Solvents (DESs) which are usually made up of a combination of biorenewable hydrogen bond acceptors [e.g., ammonium salts like choline chloride $(\mathrm{ChCl})]$ and hydrogen bond donor (e.g., water, glycerol) ${ }^{9}$ have also shown great promise as nonconventional media for air and moisture compatible organolithium synthesis as demonstrated recently by our groups for nucleophilic arylation/alkylation of ketones, imines and nitriles ${ }^{10}$ as well as anionic polymerization of styrenes. ${ }^{11,12}$ Remarkable, in some of these examples, higher yields and selectivities were achieved than when using inert atmosphere protocols. Expanding even further the synthetic applications of polar organometallic chemistry in water, herein we report a new protocol that pairs these operational breakthroughs with an organocatalytic transformation, uncovering a novel one-pot tandem approach to access highly-substituted tertiary alcohols.

By eliminating the need of isolation and purification of reaction intermediates (and subsequently minimizing chemical waste generation, reaction times and energy consumption), one-pot tandem processes are highly useful and efficient green approaches in modern synthesis for the production of organic molecules. ${ }^{13}$ More often than not, these protocols tend to use the same type of transformational tools (metal-, main-group element-, bio- or organocatalysts) throughout all the tandem process, whereas the number of examples which combine different methodologies is scarce, especially those that also employ sustainable solvents. In this regard recently we have successfully combined transition-metal-catalysis in water or DESs with (Scheme 1a): i) chemoselective addition of organolithium reagents (RLi) to ketones as transient intermediates; ${ }^{14}$ and ii) enzymatic enantioselective bioamination (transaminases, 
ATA) or bioreduction (ketoreductases, KRED) of in-situ generated prochiral ketones. ${ }^{15}$ Breaking new ground in this evolving field, we combine for the first time organocatalysis and organolithium chemistry in water as a new methodology to prepare highly substituted tertiary alcohols. The approach employed comprises the organo-catalyzed oxidation of secondary alcohols (furnishing ketones in-situ as intermediates) followed by subsequent chemoselective and fast addition of organolithium reagents affording the relevant tertiary alcohols. Reactions were carried out under one-pot conditions in aqueous media, under air and at room temperature (Scheme $1 \mathrm{~b}$ ).

$$
\text { Previous work (Scheme 1a): }
$$

This work (Scheme 1b):

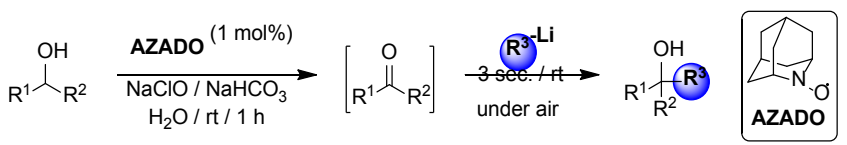

Scheme 1. Design of hybrid one-pot tandem combinations that rely on different organic synthetic tools (transition metals, $s$-block reagents or organocatalysts) in water or Deep Eutectic Solvents (DESs).

Building on previous studies reported by some of us, in which we have uncovered the efficient organocatalytic activity of AZADO (2azaadamantane $\mathrm{N}$-oxyl, 1a) in combination with an aqueous solution of $\mathrm{NaClO}$ (2a, acting as external oxidant) as a straightforward and operationally simple method for the selective oxidation of secondary alcohols ${ }^{16}$; we selected, as a model reaction, the oxidation of the benzylic-type alcohol 3a (see Table 1). Firstly, we assessed if the use of toxic organic co-solvents such as $\mathrm{PhCF}_{3}, \mathrm{CH}_{2} \mathrm{Cl}_{2}$ or $\mathrm{CH}_{3} \mathrm{CN}$ was actually required in order to achieve quantitative yields of the desired ketone $4 \mathrm{a}$ (entries 1-3, Table 1). ${ }^{16}$

Table 1. Oxidation of 1-phenylpropan-1-ol (3a) into propiophenone (4a) organocatalyzed by AZADO (1a) or minoxidil (1) in combination with different external oxidants (2a-c) in aqueous media, at room temperature and under air ${ }^{a}$

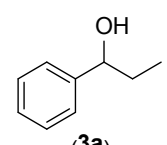

3a)

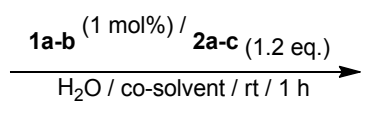

\begin{tabular}{|c|c|c|c|c|}
\hline entry & Organocat. & Oxidant & Co-solvent $^{c}$ & Yield (\%) ${ }^{d}$ \\
\hline 1 & AZADO (1a) & aq. $\mathrm{NaClO}^{b}(2 \mathrm{a})$ & $\mathrm{PhCF}_{3}$ & $95 \%$ \\
\hline 2 & AZADO (1a) & aq. $\mathrm{NaClO}^{b}(2 \mathrm{a})$ & $\mathrm{CH}_{2} \mathrm{Cl}_{2}$ & $99 \%$ \\
\hline 3 & AZADO (1a) & aq. $\mathrm{NaClO}^{b}(2 \mathrm{a})$ & $\mathrm{CH}_{3} \mathrm{CN}$ & $99 \%$ \\
\hline 4 & AZADO (1a) & aq. $\mathrm{NaClO}^{b}(2 \mathrm{a})$ & - & $99 \%$ \\
\hline 5 & AZADO (1a) & $\mathrm{KMnO}_{4}(\mathbf{2 b})$ & - & $69 \%$ \\
\hline 6 & AZADO (1a) & $\mathrm{I}_{2}(2 \mathrm{c})$ & - & $13 \%$ \\
\hline 7 & Minoxidil (1b) & aq. $\mathrm{NaClO}^{b}(2 \mathrm{a})$ & - & $17 \%$ \\
\hline 8 & Minoxidil (1b) & $\mathrm{KMnO}_{4}(\mathbf{2 b})$ & - & $42 \%$ \\
\hline 9 & Minoxidil (1b) & $\mathrm{I}_{2}(2 \mathrm{c})$ & - & $4 \%$ \\
\hline
\end{tabular}

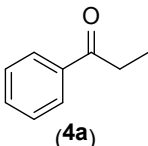

${ }^{a}$ General Conditions: Reactions performed under air, at rt using $1 \mathrm{mmol}$ of the alcohol $3 \mathrm{a}(270 \mathrm{mM}) .{ }^{b} 0.40 \mathrm{M}$ aqueous solution of $\mathrm{NaClO}(\mathrm{pH} 7.9,3.7 \mathrm{~mL})$ was used. ${ }^{c} 219 \mu \mathrm{L}$ of the organic co-solvent were employed. ${ }^{d}$ Isolated yields

Pleasingly, we found that 1-phenylpropan-1-ol (3a) can be quantitatively converted into the desired propiophenone (4a, entry 4 , Table 1) under the same reaction conditions ( $1 \mathrm{~h}, \mathrm{rt}, 270 \mathrm{mM}$ loading of substrate) in the absence of these toxic organic cosolvents. For completeness of this parametrization, we also studied the use of other co-oxidants for AZADO (1a) like $\mathrm{KMnO}_{4}$ (2b, entry 5 , Table 1 ) or $\mathrm{I}_{2}$ (2c, entry 6 , Table 1 ) finding in both cases reduced activity (69-13\%). Interestingly, we found that when AZADO was replaced by a different amine $\mathrm{N}$-oxide such as minoxidil (1b, 6piperidin-1-ylpyrimidine-2,4-diamine 3-oxide) in combination with the aforementioned sacrificial oxidants ( $\mathrm{NaClO}$, entry $7 ; \mathrm{KMnO}_{4}$, entry 8; and $I_{2}$, entry 9; Table 1 ) significant lower conversions were observed (4-42\% yields), highlighting the high efficiency of the organocatalytic/oxidation $\mathrm{NaClO} / \mathrm{AZADO}$ system while operating in aqueous media.

Encouraged by these initial results, which show that we can quantitatively prepare ketones from secondary alcohols in aqueous media at room temperature and in the absence of any organic cosolvents, we next pondered if this transformation could also be part of a modular combination, where the relevant synthesized ketones could subsequently undergo chemoselective alkylation using a onepot approach while operating in aqueous media under air.

Towards this target, it should be noted that $s$-block polar organometallic reagents such as Grignard (RMgX) and organolithium (RLi) reagents are widely used for addition reactions to ketones, being a fundamental and versatile method to generate $\mathrm{C}-\mathrm{C}$ bonds to access tertiary alcohols. ${ }^{17}$ Notwithstanding, the chemoselectivity of these processes can be compromised by the formation of undesired reduction and/or enolization products, resulting from competing $\beta$ hydride elimination and deprotonation reactions respectively. ${ }^{18}$ Recently our groups have shown using DESs which combine ammonium salt choline chloride $(\mathrm{ChCl})$ with water or glycerol $(\mathrm{Gly})$ as reaction media, Grignard and organolithium reagents can promote room temperature chemoselective ketone alkylation/arylation reactions. ${ }^{10}$ Along with greater selectivities and milder reaction conditions, these reactions are compatible with the presence of air. ${ }^{10}$ However, DESs are not compatible with the organocatalytic oxidation system AZADO/NaClO, as the addition of $\mathrm{NaClO}$ to the eutectic reaction media produced the formation of $\mathrm{Cl}_{2}$ gas through the expected comproportionation reaction between the $\mathrm{Cl}^{-}$and $\mathrm{ClO}^{-}$ anions.

We next assessed whether this tandem oxidation/alkylation approach could be compatible with aqueous media. Thus, we selected as a model reaction the AZADO/NaClO organocatalyzed oxidation of 1-phenylpropan-1-ol (3a) into ketone 4a followed by the direct addition of $n$-BuLi (Table 2). Firstly, the reaction mixture containing the alcohol 3a $(270 \mathrm{mM})$ and the organocatalytic oxidation system (AZADO/NaClO) was allowed to react in aqueous media, at room temperature and in the presence of air for $1 \mathrm{~h}$ to trigger the expected oxidation. As soon as the total conversion of $3 a$ into propiophenone (4a) was observed ( 1 h, GC analysis), $n$-BuLi was directly added to the reaction mixture (without any intermediate step of isolation or purification of ketone $4 a$ ), in the absence of protecting atmosphere and at room temperature (conditions usually forbidden for RLi reagents). ${ }^{17}$ Astonishing, the almost instantaneous formation ( $3 \mathrm{~s}$ ) of the relevant tertiary alcohol $\mathbf{5 a}$ was observed, finding a significantly improved yield of $76 \%$ when three equivalents of the organolithium reagent were employed (entry 4, Table 2). ${ }^{19}$ However, gradually decreasing the number of equivalents of $n$-BuLi (from 3 to 1 ) produces a concomitant diminution of the nucleophilic 
addition of $n$-BuLi into the in-situ formed ketone $4 a$, from 76 to $23 \%$ yield of the final tertiary alcohol $\mathbf{5 a}$ (entries 1-4, Table 2). At this point, it is important to note that in all cases (entries 1-4, Table 2) the one-pot tandem construction of the tertiary alcohol 5a occurred with total chemoselectivity, as no side products were observed in the crude reaction mixture (containing only the desired final product $\mathbf{5 a}$ and the unreacted ketone $4 a$ ). We next decided to expand the scope to other organolithium (RLi) or organomagnesium (RMgX) reagents.

Table 2. Direct conversion of 1-phenylpropan-1-ol (3a) into tertiary alcohols $\mathbf{5 a - d}$ through the one-pot combination of the organocatalyzed (AZADO/ $\mathrm{NaClO}$ ) oxidation of alcohols and the chemoselective addition of RLi/RMgX in aqueous media, at room temperature and in the presence of air. ${ }^{\circ}$

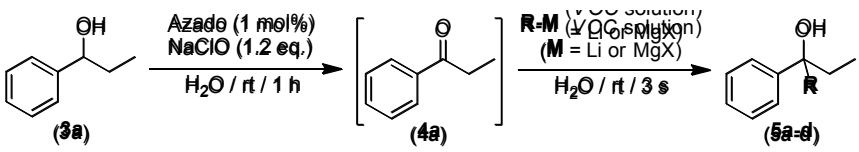

\begin{tabular}{ccccc}
\hline entry & R-M & Equivalents & Product & ${\text { Yield }(\%)^{c}}^{c}$ \\
\hline 1 & $n-B u L i$ & 1 & $5 \mathbf{a}$ & $23 \%$ \\
2 & $n-B u L i$ & 2 & $\mathbf{5 a}$ & $47 \%$ \\
3 & $n-B u L i$ & 2.5 & $5 \mathbf{a}$ & $62 \%$ \\
4 & $n-B u L i$ & 3 & $\mathbf{5 a}$ & $76 \%$ \\
5 & MeLi & 3 & $\mathbf{5 b}$ & $70 \%$ \\
6 & $s e c-B u L i$ & 3 & $\mathbf{5 c}$ & $83 \%$ \\
7 & PhLi & 3 & $\mathbf{5 d}$ & $35 \%$ \\
8 & $n-B u M g C l$ & 3 & $\mathbf{5 a}$ & -
\end{tabular}

a General Conditions: Reactions performed under air, at $\mathrm{rt}$ using $1 \mathrm{mmol}$ of the alcohol $3 a(270 \mathrm{mM})$. $0.40 \mathrm{M}$ aqueous solution of $\mathrm{NaClO}(\mathrm{pH} 7.9,3.7 \mathrm{~mL})$ was used. ${ }^{b}$ Commercially available $1.6 \mathrm{M}$ solution of $n$-BuLi in hexanes, $1.6 \mathrm{M}$ solution of $\mathrm{MeLi}$ in $\mathrm{Et}_{2} \mathrm{O}, 1.4 \mathrm{M}$ solution of sec-BuLi in cyclohexane, $1.8 \mathrm{M}$ solution of PhLi in dibutyl ether and $2.0 \mathrm{M}$ solution of $n-\mathrm{BuMgCl}$ in $\mathrm{Et}_{2} \mathrm{O}$ were directly added at $\mathrm{rt}$ and under air. ${ }^{C}$ Isolated yields

Interestingly we found that other aliphatic organolithium reagents such as MeLi (entry 5, Table 2); sec-BuLi (entry 6, Table 2) can selectively add across the $\mathrm{C}=\mathrm{O}$ double bond of $\mathbf{4 a}$ under the above mentioned conditions, affording alcohols $\mathbf{5 b}$ and $\mathbf{5 c}$ in excellent yields (70 and $83 \%$ respectively) whereas using less nucleophilic PhLi, $\mathbf{5 d}$ is obtained in a $35 \%$ yield (entry 6 , Table 2 ). The high conversions and chemoselectivities observed while operating at room temperature are particularly noteworthy for sec-BuLi which has a greater tendency to undergo $\beta$-hydride elimination, and has to be usually stored at low temperatures $\left(2-8^{\circ} \mathrm{C}\right)$ to avoid degradation via this side reaction. Furthermore, Ishihara has shown that when $n$ BuLi is employed as an alkylating reagent towards enolizable ketones variable amounts of the aldol condensation products are obtained even when operating at $-78^{\circ} \mathrm{C}$ in THF under strict inert atmosphere conditions. ${ }^{18 \mathrm{~b}}$ On the other hand, this method does not seem compatible with Grignard reagents and when $n-\mathrm{BuMgCl}$ was employed as an alkylating reagent, alcohol 5 a could not be detected (entry 8, Table 2). This lack of reactivity is consistent with previous studies in the addition of Grignard reagents to carbonyl compounds in water that have shown that $n-\mathrm{BuMgCl}$ undergoes complete protonation in competition with carbonyl addition. ${ }^{20}$ At this point we would like to highlight the use of commercially available solutions of RMgX and RLi reagents containing different organic solvents, namely hexane for $n$-Buli, diethyl ether for MeLi, and dibutyl ether for PhLi. We hypothesize that besides the intrinsic reactivity of each reagent, both the nature and the amount of the organic accompanying solvent is critical for the outcome of the addition reaction, based on the premise that the reactions are taking place under "on water" conditions. ${ }^{21}$ Accordingly, the more water-immiscible the RLi solvent and the smaller concentration of the commercially available organolithium solution, the more favoured that interface and therefore the better performance. In good agreement, the highest yield was obtained in cyclohexane (sec-BuLi, entry 6), the most hydrophobic solvent of the series and with the smaller concentration (1.4 M), followed by hexane ( $n$-BuLi, $1.6 \mathrm{M}$, entry 4 ) and finally the ether solvent (entries 5 and 7). In the same line, another interesting finding was that when acetophenone was reacted with $n$-BuLi using water as a reaction medium under exactly the same conditions depicted in Table 2, the alkylation reaction is suppressed. Whereas, with propiophenone (4a), alcohol $\mathbf{5 a}$ was obtained in a $76 \%$. A plausible explanation could be the different solubilities in water of both ketones, with acetophenone showing a greater solubility in water than $\mathbf{4 a}$, again in agreement with the possibility that these addition reactions are taking place under "on water" conditions. ${ }^{21}$ "On water" reactions are thought to occur at the organic/liquid water interface with water insoluble reactants. In this regard Capriati et al. have recently postulated that interfacial $\mathrm{H}$-bonding to water insoluble carbonyl compounds embedded at the organic/water interphase may play a key role in favouring "on-water" nucleophilic additions promoted by RMgX and RLi reagents. ${ }^{8 \mathrm{~d}, 8 \mathrm{~h}}$ Once the scope of the $s$-block highly-polar organometallic reagents was established, we decided to further expand this one-pot tandem oxidation/RLi addition in aqueous media to a series of secondary alcohols (3a-f, Table 3) and $n$-BuLi or sec-BuLi as alkylating reagents.

Table 3. AZADO/NaClO organocatalyzed oxidation of secondary alcohols (3a-f) combined with the chemoselective addition of organolithium reagents in a one-pot process, at room temperature, in the presence of air and in aqueous media.

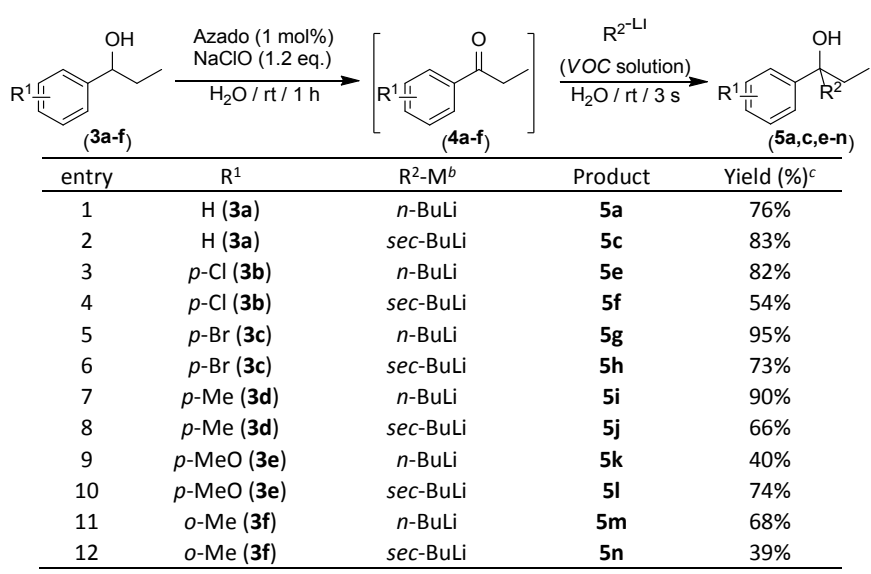
${ }^{a}$ General Conditions: Reactions performed under air, at rt using $1 \mathrm{mmol}$ of the desired alcohol 3a-f ( $270 \mathrm{mM})$. 0.40 M aqueous solution of $\mathrm{NaClO}(\mathrm{pH} 7.9,3.7 \mathrm{~mL})$ was used. ${ }^{b}$ Commercially available $1.6 \mathrm{M}$ solution of $n$-BuLi in hexanes and $1.4 \mathrm{M}$ solution of sec-BuLi in cyclohexane were directly added at $\mathrm{rt}$ and under air. ${ }^{c}$ Isolated yields

We found that this method tolerates a variety of functional groups in the aromatic scaffold of the starting alcohols 3a-f being compatible with the presence of either electron-withdrawing (3b-c, entries 3-6) or electron-donating groups (3d-f, entries 7-12) giving rise to the desired tertiary alcohols $\mathbf{5 a , c , e - n}$ in good yields (up to $95 \%$ ), and without the need of any halfway step of isolation or purification of the intermediate ketones $\mathbf{4 a - f}$, which were always formed in quantitative yields after $1 \mathrm{~h}$ of reaction (GC analysis). In general, better yields of the final tertiary alcohols were obtained when $n$-BuLi (even entries in Table 3) was used as alkylating reagent. 
This experimental observation is in good agreement with the expected lower nucleophilic activity of the more sterically demanding sec-BuLi when compared with linear $n$-BuLi. ${ }^{17}$ At this point, it is important to note that although electronic properties of the substituents in the aromatic ring have only a modest effect, the presence of an ortho-substituent (entries 11-12, Table 3) produces a considerable decrease in the yield of the final alcohols $\mathbf{5 m}-\mathbf{n}$. This experimental observation seems to indicate that the electronic effects have a smaller impact than steric hindrance which can be associated to the virtually instantaneous nature of the addition reactions in aqueous media. Interestingly, other possible competing processes with the addition reaction or RLi to ketones like: $i$ ) metalation of benzylic position in substrates $\mathbf{3 d - f}$; or ii) Li-halogen exchange processes in alcohols $\mathbf{3 b} \mathbf{b}-\mathbf{c}$, were not detected.

In conclusion, edging closer towards the development of air and water compatible organolithium chemistry, these findings have uncovered the potential of using water as an alternative sustainable reaction medium for tandem protocols that combine organocatalysis with the use of organolithium reagents. Interestingly water not only enables more environmentally benign reaction conditions (under air, room temperature) but also greater selectivities than when using conventional organic solvents under inert atmosphere conditions.

We thank the Spanish MINECO (projects CTQ2017-88357-P, CTQ2016-81797-REDC and CTQ2016-75986-P). J.G.-A. is indebted to PhosAgro/UNESCO/IUPAC for the award of a "Green Chemistry for Life Grant". EH thanks the University of Bern (EH) for the generous sponsorship of this research. DE thanks Gobierno de Principado de Asturias and the EU for the award of a postdoctoral fellowship (Clarín-COFUND program).

\section{Conflicts of interest}

"There are no conflicts to declare".

\section{Notes and references}

Keywords: water $\bullet$ organolithium $\bullet$ alcohol oxidation $\bullet$ tandem protocols • sustainable chemistry $\bullet$ organocatalysis

1 (a) H. C. Hailes, Org. Proces Res. Dev., 2007, 11, 114; (b) R. N. Butler and A. G. Coyne, Chem. Rev., 2010, 110, 6302.

2 P. T. Anastas and J. C. Warner, Green Chemistry Theory and Practice, Oxford University Press, Oxford, 1998.

3 For some references on how to increase the greenness of using water as solvent by removing contaminants from wastewater, see: (a) T. W. Seow, C. K. Lim, M. H. M. Nor, M. F. M. Mubarak, C. Y. Lam, A. Yahya and Z. Ibrahim, Int. J. Appl. Environ. Sci., 2016, 11, 111; (b) C. A. Martínez-Huitle and S. Ferro, Chem. Soc. Rev., 2006, 35, 1324.

4 T. Kitanosono, K. Masuda, P. Xu and S. Kobayashi, Chem. Rev., 2018, 118, 679.

5 M. O. Simon and C.-J. Li, Chem. Soc. Rev., 2012, 41, 1415.

6 (a) J. García-Álvarez, Eur. J. Inorg. Chem., 2015, 5147; (b) J. García-Álvarez, E. Hevia, V. Capriati, Eur. J. Org. Chem., 2015, 6779; (c) J. García-Álvarez, E. Hevia, V. Capriati, Chem. Eur. J., 2018, 24, 14854

7 (a) V. Capriati, F. M. Perna and A. Salomone, Dalton Trans., 2014, 43, 14204; (b) U. Wietelmann and J. Klett, Z. Anorg. Allg. Chem., 2018, 644, 194.

8 (a) T. Laube, J. D. Dunitz and D. Seebach, Helv. Chim. Acta 1985, 68, 1373; (b) P. G. Cozzi and L. Zoli, Angew. Chem. Int.
Ed., 2008, 47, 4162; (c) V. Juste-Navarro, I. Delso, T. Tejero and P. Merino, Chem. Eur. J., 2016, 22, 11527; (d) L. Cicco, S. Sblendorio, R. Mansueto, F. M. Perna, A. Salomone, S. Florio and V. Capriati, Chem. Sci., 2016, 7, 1192; (e) D. Seebach, Isr. J. Chem., 2017, 57, 55; (f) Y. Gimbert, D. Lesage, C. Fressigné and J. Maddaluno, J. Org. Chem., 2017, 82, 8141; (g) I. Koehne, S. Bachmann, R. Herbst-Irmer and D. Stalke, Angew. Chem. Int. Ed., 2017, 56, 15141; (h) G. Dilauro, M. Dell'Aera, P. Vitale, V. Capriati and F. M. Perna, Angew. Chem. Int. Ed., 2017, 56, 10200; (i) G. Dilauro, A. F. Quivelli, P. Vitale, V. Capriati and F. M. Perna, Angew. Chem. Int. Ed., 2019, 58, 1799.

9 (a) A. P. Abbott, G. Capper, D. L. Davies, R. K. Rasheed and V. Tambyrajah, Chem. Commun., 2003, 70; (b) M. Francisco, A. van den Bruinhorst and M. C. Kroon, Angew. Chem. Int. Ed., 2013, 52, 3074; (c) E. L. Smith, A. P. Abbott and K. S. Ryder, Chem. Rev., 2014, 114, 11060; (d) D. A. Alonso, A. Baeza, R. Chinchilla, G. Guillena, I. M. Pastor and D. J. Ramón, Eur. J. Org. Chem., 2016, 612; (e) Deep Eutectic Solvents: Synthesis, Properties, and Applications (Eds: D. J. Ramón and G. Guillena), Wiley-VCH, Weinheim, 2019; (f) F. M. Perna, P. Vitale and V. Capriati, Curr. Opin. Green Sustainable Chem., 2020, 21, 27.

10 (a) C. Vidal, J. García-Álvarez, A. Hernán-Gómez, A. R. Kennedy and E. Hevia, Angew. Chem. Int. Ed., 2014, 53, 5969; (b) C. Vidal, J. García-Álvarez, A. Hernán-Gómez, A. R. Kennedy and E. Hevia, Angew. Chem. Int. Ed., 2016, 55, 16145; (c) M. J. Rodríguez-Álvarez, J. García-Álvarez, M. Uzelac, M. Fairley, C. T. O'Hara and E. Hevia, Chem. Eur. J., 2018, 24, 1720.

11 A. Sánchez-Condado, G. A. Carriedo, A. Presa Soto, M. J. Rodríguez-Álvarez, J. García-Álvarez and E. Hevia, ChemSusChem, 2019, 12, 3134.

12 For other recent examples in the use of DES in the field of $s$ block chemistry, see: (a) V. Mallardo, R. Rizzi, F. C. Sassone, R. Mansueto, F. M. Perna, A. Salomone and V. Capriati, Chem. Commun., 2014, 50, 8655; (b) F. C. Sassone, F. M. Perna, A. Salomone, S. Florio and V. Capriati, Chem. Commun., 2015, 51, 9459; (c) C. Prandi, S. Ghinato, G. Dilauro, F. M. Perna, V. Capriati and M. Blangetti, Chem. Commun., 2019, 55, 7741

13 Y. Hayashi, Chem. Sci., 2016, 7, 866.

14 L. Cicco, M. J. Rodríguez-Álvarez, F. M. Perna, J. García-Álvarez and V. Capriati, Green Chem., 2017, 19, 3069.

15 (a) N. Ríos-Lombardía, C. Vidal, M. Cocina, F. Morís, J. GarcíaÁlvarez and J. González-Sabín, Chem. Commun., 2015, 51, 10937; (b) N. Ríos-Lombardía, C. Vidal, E. Liardo, F. Morís, J. García-Álvarez and J. González-Sabín, Angew. Chem. Int. Ed., 2016, 55, 8691; (c) M. J. Rodríguez-Álvarez, N. RíosLombardía, S. Schumacher, D. Pérez-Iglesias, F. Morís, V. Cadierno, J. García-Álvarez and J. González-Sabín, ACS Catal. 2017, 7, 7753; (d) E. Liardo, R. González-Fernández, N. RíosLombardía, F. Morís, J. García-Álvarez, V. Cadierno, P. Crochet, F. Rebolledo and J. González-Sabín, ChemCatChem, 2018, 10, 4676; (e) L. Cicco, N. Ríos-Lombardía, M. J. Rodríguez-Álvarez, F. Morís, F. M. Perna, V. Capriati, J. García-Álvarez and J. González-Sabín, Green Chem., 2018, 20, 3468.

16 (a) E. Liardo, N. Ríos-Lombardía, F. Morís, F. Rebolledo and J. González-Sabín, ACS Catal., 2017, 7, 4768; (b) E. Liardo, N. Ríos-Lombardía, F. Morís, J. González-Sabín and F. Rebolledo, Eur. J. Org. Chem., 2018, 3031; (c) L. Marx, N. Ríos-Lombardía, P. Süss, M. Höhne, F. Morís, J. González-Sabín and P. Berglund, Eur. J. Org. Chem., 2020, 4, 510.

17 (a) H. Yamataka, K. Yamada, and K. Tomioka, Addition of organolithium reagents to double bonds, in The chemistry of organolithium compounds (Eds.: Z. Rappoport, and I. Marek), Patai Series, Wiley, Chichester, 2009; (b) H. Reich, Chem. Rev., 2013, 113, 7130; (c) N. D. Bartolo, J. A. Read, E. M. Valentín and K. A. Woerpel, Chem. Rev., 2020, 120, 1513.

18 (a) S. Yamazaki and S. Yamabe, J. Org. Chem., 2002, 67, 9346; (b) M. Hatano, T. Matsumura and K. Ishihara, Org. Lett., 2005, 
7, 573; (c) M. Hatano, S. Suzuki and K. Ishihara, J. Am. Chem. Soc., 2006, 128, 9998.

19 We have observed experimentally that the addition of higher amounts of $n$-BuLi under these conditions did not increase the final yield of the desired alcohol $\mathbf{5 a}$.

20 G. Osztrovszky, T. Holm and R. Madsen, Org. Biomol. Chem., 2010, 8, 3402. However, Capriati et al. have reported that several Grignard reagents can be successfully added to carbonyl derivatives (similarly to organolithiums reagents) under "on water" conditions (see ref. 8d).

21 (a) A. Chanda and V. V. Fokin, Chem. Rev., 2009, 109, 725; (b)

R. M. Butler and A. G. Coyne, J. Org. Chem., 2015, 80, 1809;

(c) R. N. Buttler and A. G. Coyle, Org. Biomol. Chem., 2016, 14, 9945. 